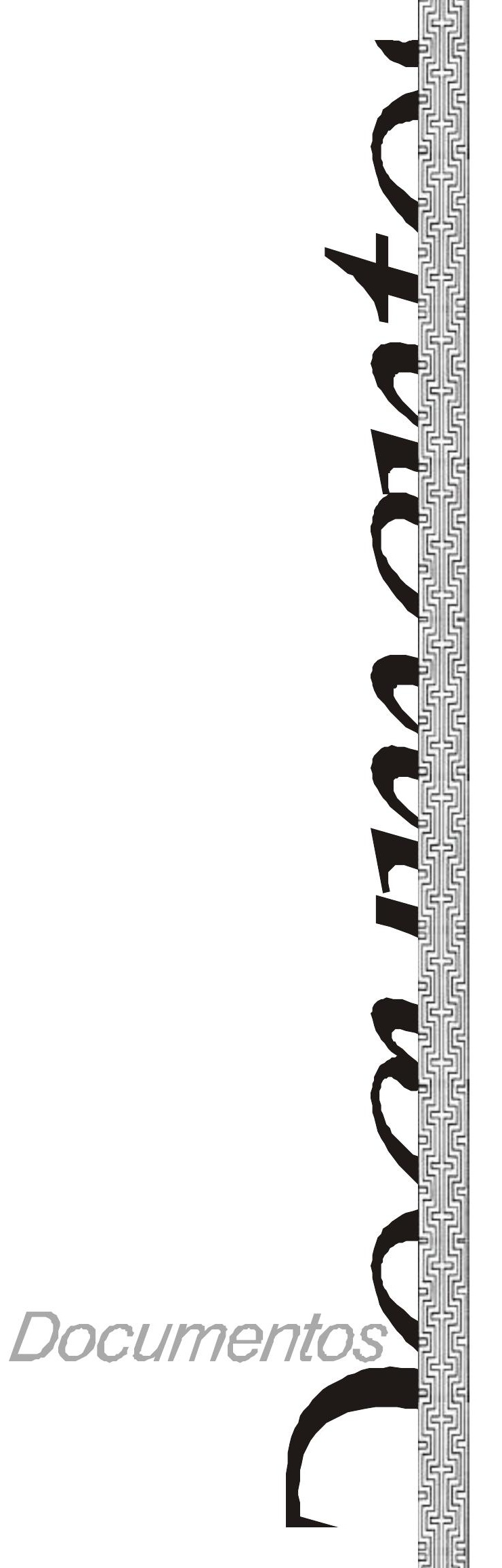





\section{Os índios Guaycuru na edição digital da Historia del Paraguay, Río de La Plata y Tucumán de Pe. Guevara}

\author{
Neimar Machado de Sousa* \\ João Paulo Zanela**
}

\section{Introdução}

Os índios Guaycuru, ou Mbayá-Guaycuru, como se refere constantemente a historiografia colonial, inicialmente constituíam um grupo que, no século XVI, habitou a região do Chaco, dividido em dois núcleos: o núcleo do sul (Guaicurú), localizado na margem ocidental do rio Paraguai, próximo à cidade de Assunção; e do norte (Mbayá), também na margem ocidental do Alto Paraguai. O trecho selecionado da "História do Paraguay, Rio da Prata e Tucumán" reproduz um relato sobre o governo de Hernandarias, em Assunção, além de mencionar a proximidade destes índios, a necessidade de reduzí-los (do latim, reduciret, conduzir) à vida civilizada via conversão Cristã.

A urgência da conversão dos índios ao cristianismo, especialmente Guaycuru e Paiaguá, que assediavam Assunção, a livre navegação do rio Paraguai e o trânsito pelos terras secas devia-se, na ótica dos governadores de Assunção `a necessidade de estabelecer os empreendimentos coloniais na região então conhecida como Províncias do Prata e viabilizá-los.

Como resultado das estratégias punitivas, massacres diretos por meio de soldados e indireto pelo choque epidemiológico, já no final do século XVI, houve o acirramento da pressão sobre os territórios controlados pelos índios. A pressão exercida pelos núcleos coloniais como resultado das incursões dos "índios cavaleiros" fez com que estas populações se deslocassem gradativamente em direção ao norte, atingindo assim as atuais terras sul-mato-grossenses na segunda metade do século XVII.

Além da pressão exercida pelo avanço espanhol no Prata, temos a destruição das missões de Itatim pelas incursões
* Professor da disciplina de História da América no Curso de História da Universidade Católica Dom Bosco. Pesquisador em História Indígena no

Programa Kaiowá e Guarani e doutorando no PPGE/ UFSCar.neimar@ucdb.br

** Acadêmico de História na Universidade Católica Dom Bosco e pesquisador no Centro de Documentação TEKO ARANDU -

Programa Kaiowá/Guarani. joaozanela@hotmail.com 
escravistas dos paulistas luso-brasileiros, notadamente a expedição de 1647, capitaneada por Raposo Tavares. Na opinião do historiador Luis Felipe de Alencastro, autor do livro O Trato dos Viventes, estas incursões mamelucas eram comuns em um estado que construiu sua economia sobre o comércio de pessoas, índios da terra e de Angola.

Uma característica dos assentamentos Mbayá-Guaicurú era a diversidade numérica e étnica devido a uma economia natural baseada no escambo de produtos entre os Guaicurú e outras populações indígenas. Além destas cabe destaque para: a) assentamentos chaquenhos, caracterizados por uma ocupação temporária, com deslocamentos constantes em busca de áreas propícias; b) assentamentos na região do Pantanal e áreas adjacentes, com assentamentos sazonais, variando de locais conforme o ciclo das inundações e da seca, e com assentamentos mais estáveis de áreas não inundáveis; c) assentamentos estáveis Kadiwéu, caracterizados por aldeias semi-sedentárias e a ocupação conjugada de acampamentos temporários, como os aterros, para as atividades subsistênciais como, por exemplo, na época das caçadas de veados (Cervidae) ou da colheita de acuri (Scheelea phalerata) e bocaiúva (Acrocomia aculeata) (Herberts, 1998, p. 20)

À subsistência Mbayá-Guaicurú, somam-se as alianças com outras etnias que forneciam produtos agrícolas, por intermédio do comércio com os Mbayá ou da troca por proteção, além das tradicionais atividades de caça, pesca e coleta, realizadas conforme os recursos faunísticos e florísticos do ambiente. $\mathrm{O}$ cultivo de produtos agrícolas somente surge com a maior estabilidade dos assentamentos a partir do século XIX. A criação de animais domésticos é desenvolvida a partir de possibilidades coloniais trazidas pelos colonizadores, destacando-se rebanhos eqüinos e bovinos. Os índios cavaleiros conforme retratados pelo pintor francês Jean Bartiste Debret, no século XIX, são uma representação interessante do hibridismo que se produziu no seio da sociedade colonial. Evidentemente cabe notar que o uso do cavalo foi bastante adequado ao estilo semi-sedentário destas populações. Por outro lado a representação da sociedade nacional dos Guaycuru como uma sociedade eqüestre aponta em direção ao parco conhecimento, além de descontextualizado, sobre as populações indígenas (Herberts, 1998).

$\mathrm{O}$ autor desta fonte, parcialmente reproduzida neste artigo, foi membro da Companhia de Jesus, nasceu no ano de 1720, na cidade de Recas, pequeno povoado nas imediações de Toledo, na Espanha. Na adolescência José Guevara estudou no instituto religioso Santo Ignácio, local onde ingressou na Cia de Jesus, assim que completou seus estudos. 
Foi mandado às Missões Jesuíticas do Paraguai para servir de professor nos colégios estabelecidos em Buenos Aires, Assunção e Córdoba. A sua principal obra, Historia del Paraguay, Río de la Plata y Tucumán, foi escrita antes de 1767 e publicada somente em 1886, em Buenos Aires, pelo jornalista oficial de estado portenho sob a ditadura de Rosas, Pedro de Angelis.

O leitor que desejar aprofundar-se nas fontes para a História Colonial do Prata, dentro da qual se insere a região sul de Mato Grosso, até aproximadamente 1750, deverá necessariamente pesquisar sobre o italiano Pedro de Angelis que, paralelamente à sua atividade de relações públicas do governo portenho, comprava papéis antigos, principalmente dos jesuítas, vendidos por colecionadores particulares, pagando muito pouco por isto, segundo detratores, para posterior publicação ou mesmo para revendê-los. Este periodista colonial chegou a vender parte de sua coleção para o governo do Império do Brasil sendo, na negociata, intermediado pelo Barão do Rio Branco. Evidentemente que a indefinição das fronteiras, naquele período aumentava o valor daqueles papéis.

O trecho do documento abaixo reproduzido foi obtido na Biblioteca Virtual Miguel de Cervantes (www.cervantesvirtual.com), inaugurada em julho de 1999. Esta biblioteca eletrônica é um esforço da iniciativa privada e do governo espanhol para preservar e ampliar o acesso a documentos históricos e literários em língua espanhola espalhados em arquivos e bibliotecas. O projeto original é da Universidade de Alicante Espanha e financiado pelo Banco Santander Central Hispano e Fundação Marcelino Botín para a edição e difusão, por meio digital, do patrimônio bibliográfico, documental e crítico da cultura espanhola e hispanoamericana. Além da obra do Pe. Guevara, o pesquisador encontrará no catálogo obras raras e importantíssimas para a história indígena, no período colonial e para a região do atual Mato Grosso do Sul.

\section{§ XVIII}

Gobierno de Hernando Arias de Saavedra (1602-1609)

Con el nuevo siglo empezó la provincia del Río de la Plata a respirar aires más benignos; los tumultos civiles que todo lo consumen, se acabaron con muerte de los principales motores; los indios desengañados con la experiencia, y humillados con el castigo, no daban cuidado a la milicia española; los gobernadores, más a propósito para descuadernar provincias que para gobernarlas, habían finalizado sus días.

Por muerte de don Diego Valdez de la Banda entró a gobernar - 171 - 
Hernando Arias de Saavedra, o por elección según la cédula del Emperador Carlos V, otras veces citada, o por nominación del señor Virrey, en cuya virtud gobernó hasta el año de 1602, en que recibió cédula real fecha en 18 de diciembre de 1601 que le confería en propiedad el bastón del Río de la Plata.

Hernando Arias, pues sucedió inmediatamente a don Diego Valdez, y como tenía ánimo guerrero, emprendió algunas operaciones militares. Entró, aunque no sé puntualmente el año, a la provincia del Estrecho de Magallanes, internándose desde Buenos Aires, doscientas leguas tierra adentro. El suceso no correspondió al valor del capitán ni a la fortuna de sus empresas; porque él y su gente quedaron prisioneros de guerra en manos de bárbaros. Tuvo Hernando Arias la fortuna de soltarse de las prisiones, y entrando segunda vez con milicia más numerosa, libertó sus compañeros, y castigó los infieles.

Otras dos facciones emprendió en su gobierno, aunque no es averiguado a punto fijo el año: la conquista del Paraná, y la del Uruguay. En la primera operación, con parte de la milicia, tuvo que diferir la conquista; en la segunda perdió toda la milicia compuesta de quinientos soldados. ¡Tanto era el furor de los paranás y uruguayos, y la ciega obstinación con que defendían el originario suelo!

Por este tiempo gozaba la iglesia del Paraguay un insigne Prelado, sobrino de mi glorioso padre San Ignacio, el ilustrísimo fray Martín Ignacio de Loyola, nobilísimo Guipuzcoano. Profesaba el seráfico instituto en la provincia de San José, y resplandecía en virtudes religiosas, humildad, despejo mundano, y celo apostólico, que obligó a abandonar primero el mundo, y después la Europa, viniendo al Paraguay donde se ejercitó como fervoroso misionero en la instrucción de los gentiles. En tan santa y loable ocupación, le alcanzó la orden de restituirse a España, y como sus parientes eran nobles, consiguieron que se le hiciera propuesta de varias mitras, que no admitió su grande humildad, con edificación de la Corte. Pero como a la propuesta se añadiesen órdenes terminantes, eligió entre los muchos que le propusieron el pobre y retirado del Río de la Plata, para el cual fue presentado a 9 de octubre de 1601, y consagrado en Valladolid, pasó luego a tomar posesión de su silla episcopal.

El año de 1603 celebró sínodo, en que el celo, prudencia y discreción resplandecieron sobremanera.

Concluido el sínodo, visitó el ilustrísimo las ciudades de su obispado, con grande utilidad de sus ovejas; y le sucedió que navegando del Paraguay - 172- a Buenos Aires, halló náufragos en la orilla a los padres Marciel Lorenzana y José Cataldino, que enjugaban la ropa a los rayos del sol, y los consoló con palabras llenas de amor y suavidad. A pocos meses de llegado a Buenos Aires, murió a principios de 1606. Sucediole el ilustrísimo fray Reginaldo de Lizárraga, natural de Vizcaya en España, hijo esclarecido de la familia de predicadores, 
lustre de su provincia limense, prior y definidor de ella, provincial de Chile, y después Obispo de la Imperial, en cuyo tiempo (año de 1598) sucedió la fatalísima rebelión de los araucanos de la Concepción, adonde trasladó su cátedra episcopal. Fue promovido a la Asumpción del Paraguay, y tomó posesión el año de 1608.

La conversión de los gentiles hizo muy señalada la época del año siguiente, que lo fue también de su muerte, dando los jesuitas principio a la conversión del guayrá, paraná y guaycurús. Habíanse tentado varios medios, y el de las armas no produjo el efecto deseado. Sobre eso la Real Majestad tenía expedida una cédula, en que ordenaba a Hernando Arias que procurara efectuar la pacificación de los indios por medio de la predicación, y no por el estrago y ruido de las armas. Efectivamente, el gobernador Hernando Arias y el ilustrísimo Lizárraga, suplicaron al padre Provincial Diego Torres que señalara misioneros para Guayra; y como en el padre Provincial ardía el celo de las almas, luego puso los ojos en los padres José Cataldino y Simón Malzeta, italianos de nación, y escogidos para la conversión del gentilismo guayreño.

Más gloriosa por más difícil, aunque no tan feliz en el suceso, fue la empresa de los guaycurús, nación la más inculta, vagamunda y bárbara que conoce la América Meridional. Habitaban al occidente del Paraguay, fijando a veces su acampamento en la derecera de la Asumpción sobre la margen opuesta. Nada igualaba el atrevimiento de su ánimo, y el desprecio con que miraban los españoles, contra los cuales se hallaban en la sazón más irritados que nunca; porque intentando asaltar la ciudad en la noche de la fiesta de la Asumpción de este año, cuando divertidos con el regocijo pensaban en solazarse, los previno Hernando Arias matando algunos de ellos, e irritando los demás para la venganza. Tal era el estado de los guaycurús, desesperado a juicio de los mas, e incapaz de admitir el yugo de la ley de Cristo.

A don Pedro Mercado y Peñaloza, sucedió el año de 1600, en el gobierno de Tucumán, don Francisco Martínez de Leiva, caballero del hábito de Santiago, más memorable en las historias chilenas, por su valor - 173 contra los araucanos que en las tucumanas por sus facciones militares; o porque sosegados los indios no ofrecieron ejercicio a su valor, o porque la muerte aceleró los pasos y cortó antes de tiempo el hilo de su vida. Ocupó su lugar don Francisco Barraza y Cárdenas; pero su gobierno, más breve que el de su antecesor, finalizó la muerte el año de 1605. Sucediole Alonso Ribera, célebre en las campañas de Flandes, defensa de Cambray, sorpresa de Amiens en el ardid del carro de nueces, operaciones militares en Italia, y valor experimentado en Chile. Su gobierno en Tucumán por ahora sólo ofrece de particular el haber humillado al orgulloso calchaquí, al cual puso freno el año de 1607 dentro del valle de Londres, con una ciudad que llamó San Juan de 
Ribera. El año de 1609 deshizo la villa de Madrid de las dos Juntas, y la incorporó con la de Esteco, trasladando ambas a dos leguas de la villa de Madrid, de esta banda del Río Salado.

Proseguía en el gobierno de su iglesia el ilustrísimo fray Fernando Trejo, ejemplar de prelados, celando con incomparable vigilancia el bien espiritual de sus ovejas, tan padre de los pobres en lo que repartía de sus rentas, como pastor amoroso en la defensa y protección de su rebaño, oprimido a la sazón con extorsiones indecorosas. Defendió los límites de su obispado contra la pretensión del ilustrísimo don Alonso Ramírez de Vergara, que se apropiaba el derecho a los pueblos de Humaguaca y Casabindo.

\section{Referências}

CORTESÃO, Jaime (Org.). Jesuítas e bandeirantes no Itatim (1549-1640). Rio de Janeiro: Biblioteca Nacional, Divisão de Obras Raras e Publicações. v. I, 1951.

GUEVARA, José. Historia del Paraguay, Río de la Plata y Tucumán. Disponível em: http://www.cervantesvirtual.com . Acesso em: 01 maio 2006.

HERBERTS, Ana Lúcia. OS MBYÁ-GUAYCURU: área, assentamento, subsistência e cultura material. Dissertação de Mestrado - São Leopoldo: Unisinos, 1998.

Recebido em 26 de maio de 2006.

Aprovado para publicação em 7 de junho de 2006.

152 Neimar Machado de SOUZA; João Paulo ZANELA. Os índios Guaycuru na... 